\title{
TWO CASES OF HAND-SCHÜLLER-CHRISTIAN DISEASE IN INFANCY
}

\author{
BY \\ F. W. NASH and J. B. CAVANAGH \\ From the Children's Department and the Bernhard Baron Institute of Pathology, The London Hospital
}

(RECEIVED FOR PUBLICATION JANUARY 15, 1952)

The diversity of the clinical features of HandSchüller-Christian disease is well recognized. Although it is a disorder affecting chiefly young children, its occurrence in the first year of life is rare.

The two cases presented here indicate that the form of the disease found in infants tends to be more rapid in its course and the lesions more widespread than in older children. At the same time they appear clinically and in certain pathological respects to occupy a position intermediate between the more common varieties of Hand-SchüllerChristian disease and the non-lipoid reticuloendotheliosis of infants known as Letterer-Siwe disease. It is considered that this report provides further evidence in support of the view that these two conditions are closely related, particularly on clinical grounds, although some pathological evidence is brought forward to suggest that there may be good reason to separate Letterer-Siwe disease and the acute variety of Hand-Schüller-Christian disease on the basis of histology.

\section{Case Reports}

Case 1. Shirley T. was admitted to The London Hospital on October 25, 1944, at the age of 9 months. Her parents and an elder brother and sister were quite well, and the pregnancy and labour had been normal. There was some difficulty with feeding until the age of 6 weeks when breast feeding was replaced by a cow's milk mixture. At the age of 3 weeks her mother noticed that there were three red spots on the roof of the mouth. The significance of this observation is not known and no further mention of it is made in the case notes.

At the age of 4 months (five months before admission) the right side of the face became swollen. At first the child was thought to be suffering from mumps but shortly afterwards she was admitted to a hospital near her home, and the cervical lymph nodes were incised. The only material obtained at the operation was said to be congealed blood. The lymph nodes on both sides of the neck increased in size and the child's general condition deteriorated rapidly.

On admission she was extremely ill, pale, dyspnoeic and cyanosed. The temperature was $96^{\circ} \mathrm{F}$., the pulse 154 per minute and respirations 86 per minute. Large subcutaneous masses were found on both sides of the neck. They were firm, smooth, and fixed to the deep structures. The percussion note at both posterior lung bases was impaired and coarse crepitations were heard in all areas. The abdomen was very distended, the liver just palpable, and the spleen was firm and enlarged to three fingersbreadths ( 2 in.) below the costal margin. There was no evidence of free fluid. Other systems were normal.

The urine was normal.

Examination of the blood showed: haemoglobin, $63 \%(9.3$ g. $\%)$; red blood cells, 3,300,000 per c.mm.; colour index, 0.95 ; leucocytes, 15,850 per c.mm. (neutrophils $60 \%$, eosinophils $2 \%$, lymphocytes $36 \%$, monocytes $2 \%$ and 1 normoblast in counting 200 white cells).

A radiograph of the chest showed numerous soft opacities scattered throughout both lung fields presenting a 'snow storm' appearance. There was also a large mass occupying the superior mediastinum.

Radiographs of the skull and spine revealed defects in the frontal, parietal and occipital bones, and collapse of the body of the ninth dorsal vertebra. (It is regretted that the original $x$-ray films of the patient have been mislaid, so that their reproduction is not possible.)

The child was nursed in an oxygen tent and her condition improved slightly. There was some pyrexia $\left(100^{\circ}-101^{\circ} \mathrm{F}\right.$.) which became more marked shortly before death. She received two treatments with deep $x$-rays to the lung fields, and immediately after the second she became extremely dyspnoeic and died suddenly seven days after admission.

\section{Pathological Findings}

The following is a summary of necropsy (P.M. 223/44) performed 20 hours after death: bronchopneumonia, severe emphysema and Hand-Schüller-Christian disease, with infiltration of the thymus, lungs, liver, lymph nodes and bones.

Macroscopic Appearances. The following were noted.

Thymus. The gland was of normal shape, rubbery and flexible with, on section, a coarse reticulum of pink and grey fibrous areas separating areas of a bright yellow, lipoidal appearance. 
Faucial and Fharyngeal Tonsils. These were normal.

LYMPH NoDes. The occipital and cervical groups were enlarged (up to $3.5 \times 2.5 \mathrm{~cm}$.) with soft, swollen and purple cut surfaces shouing a few pale, yellowish grey areas. The gastro-coronary and coeliac groups were slightly enlarged with pale, grey, yellow-tlecked cut surfaces. The bronchial, axillary and mesenteric groups appeared normal.

SPLEEN. The spleen was slightly enlarged $(21 \cdot 3$ g.) with a normal cut surface.

LIVER. The liver weighed $226.8 \mathrm{~g}$., and numerous rounded and stellate grey fibrous nodules (up to $1 \cdot 0$ $\mathrm{cm}$. diameter), sparsely speckled with yellow, were scattered throughout the cut surfaces.

LUNGs. Both were beset everywhere with cysts (up to $0.9 \mathrm{~cm}$. diameter) often separated by fibrous strands. Confluent nodules resembling organizing bronchopneumonia were present in both lower lobes and in the posterior parts of both upper lobes.

BONES. Both occipital and parietal bones presented foci of bone destruction (from $0.5 \mathrm{~cm}$. diameter to 2.5 cm. diameter) filled with soft purple and orange rusty tissue not projecting above the bony surfaces. Replacement of the sella turcica by similar tissue made it difficult to remove the pituitary gland. The body of the ninth dorsal vertebra was completely collapsed and showed a subpleural projection of soft grey tissue overlying it on the right side. Small, faint grey areas of bone destruction were visible in other vertebral bodies. There was a pathological fracture in the middle of the ninth left rib covered by a subperiosteal mass of soft grey tissue. The remaining ribs were normal. Red marrow occupied the medullary cavities of the right femur, tibia and fibula, the sternum, the clavicles and the right side of the pelvis. The other bones were not examined.

KIDNEYS. The kidneys weighed $42.5 \mathrm{~g}$. and moderate parenchymatous degeneration was noted.

No abnormality was demonstrated in the heart $(28.35$ g.), gastro-intestinal tract, thyroid $(0.9 \mathrm{~g}$.$) ,$ suprarenal glands $(2.85 \mathrm{~g}$.$) , genital tract and brain$ $(772 \cdot 2$ g.). The middle ears were clean.

The body $(5 \cdot 2 \mathrm{~kg}$.) was considerably wasted and the eyes deeply sunken. No skin lesions were found.

Microscopical Examination. All paraffin sections were stained with Ehrlich's haematoxylin and eosin, Van Gieson's stain and Weigert's elastic stain. Where necessary sections were prepared by Laidlaw's and by Foot's methods for reticulin, and by Perl's method for iron. Frozen sections were stained for fat with Sudan III, for phospholipins by the Smith-Dietrich method, and for cholesterol esters by the Schultz method. WeilDavenport silver impregnation (Marshall's modification, 1948) was done on selected blocks.

The Thymus. The thymus exhibited the fullest development of the lesion, and indeed no normal thymic tissue could be identified. The gland was completely replaced by collections of cells with irregular polygonal and spindle-shaped outlines and a lightly eosinophil faintly granular cytoplasm. Their nuclei were for the most part pale and vesicular with fine chromatin strands; they were oval or twisted and indented, and showed no nucleoli. Other rather larger cells were moderately numerous and these possessed one or two distinct nucleoli and more densely staining chromatic network. Also present were rounded multinucleate giant cells, with 12 to 15 nuclei often arranged in rosette fashion and occasionally with nuclear debris in their cytoplasms (Fig. 1). These cellular collections were broken up by slender bundles of collagen fibres; scanty cords of lymphocytes and a few eosinophil leucocytes were scattered irregularly throughout. Foam cells were numerous in many areas especially in relation to the collagen bundles (Fig. 2), and many giant cells also showed vacuolation of their cytoplasm. These cells were shown to contain abundant sudanophil lipoid while other cells contained only a few cytoplasmic droplets or none at all. The polarizing microscope demonstrated in the foam cell areas abundant doubly refractile lipoid which, on heating the slide gently and allowing it to cool, reappeared as 'Maltese crosses'; the Schultz reaction was strongly positive, and the SmithDietrich test for phospholipins was abundantly positive in most vacuolated cells. With the Weil-Davenport impregnation method these mononuclear cells resembled macrophages in their strongly argyrophilic reaction and irregular cytoplasmic processes (Fig. 3); considerably enlarged and bizarre forms were numerous. The multinucleate giant cells and the rounded foam cells were also argyrophilic. Reticulin impregnations demonstrated many reticulin fibrils in relation to the collagen strands and around capillaries, but only a few delicate fibrils in the cellular areas.

LUNGS. In the lungs mononuclear cells similar to those in the thymus extensively infiltrated the alveolar walls, and formed nodular masses in which the reticulin framework of the alveoli could still be clearly traced. There was only a slight increase in reticulin fibrils in the infiltrated areas, and scanty fibrosis. Eosinophils and lymphocytes were scanty, while neutrophil leucocytes were in moderate abundance in the alveoli and alveolar walls, presumably the result of the terminal respiratory infection. Multinucleate giant cells were not numerous, and lipoid was present only in scanty quantities. Many alveoli were enormously dilated and there was considerable widening of infundibular spaces and of terminal bronchioles. While the appearances suggest that this process of dilatation was probably responsible for the larger cysts, the detailed study required to eliminate other alternatives is beyond the scope of the present article.

LIVER. In the liver similar nodular infiltration was found in the portal systems, and foam cells with sudanophil lipoid were abundant in the larger masses. Multinucleate giant cells were few and eosinophils were not seen.

LYMPH NODEs. Sections of lymph nodes sampled from axillary, upper cervical, gastro-coronary, coeliac and occipital groups all showed the same general picture of complete replacement of lymphoid tissue by mononuclear cells similar to those in the thymus and elsewhere. The capsules of the nodes were everywhere intact. The subcapsular sinuses were dilated and filled 


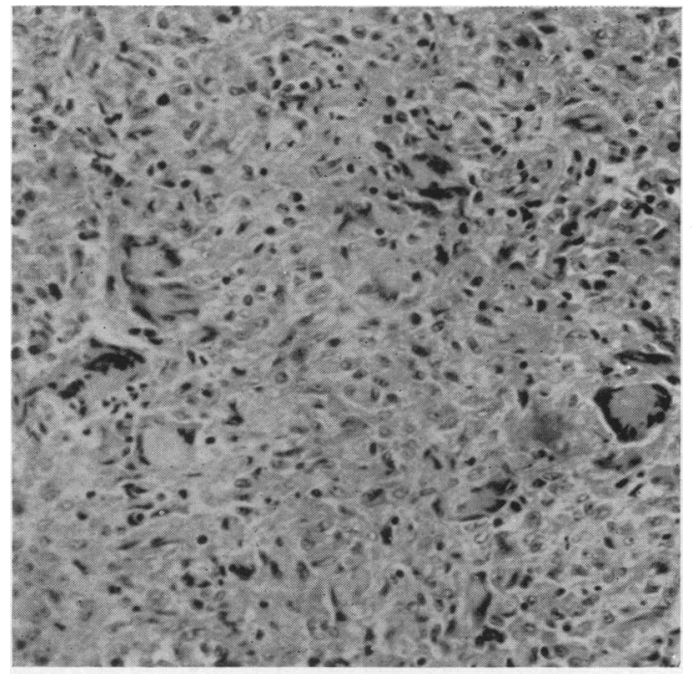

FIG. 1.

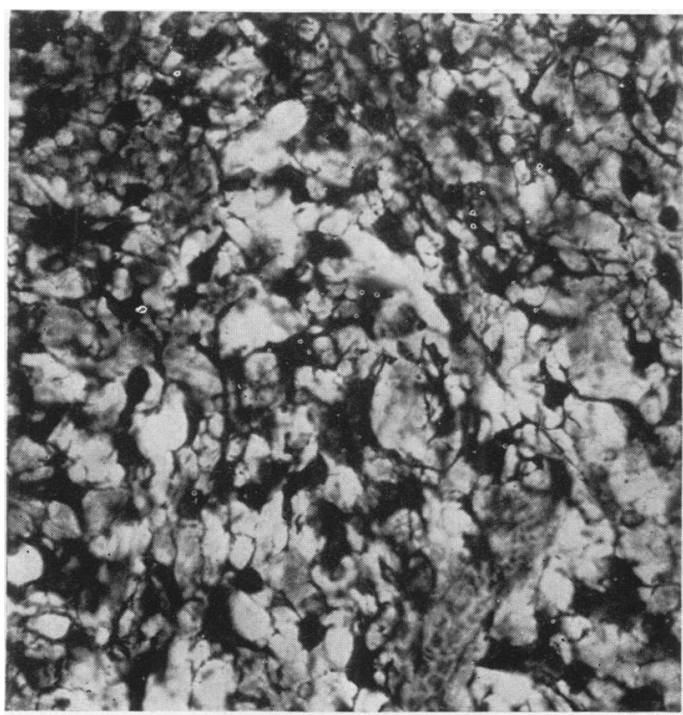

FIG. 3 .

Fig. 1.-Thymus in Case 1: closely packed non-foamy mononuclear cells and giant cells. Van Gieson's stain $(\times 175)$.

Fig. 2.-Thymus in Case 1: foam cells beside a band of collagen. Van Gieson's stain $(\times 390)$.

Fig. 3.-Thymus in Case 1: argyrophilic cells from an area not containing lipoid. Weil-Davenport silver impregnation $(\times 325)$.

FIG. 4.-Lymph node in Case 1: reticulin impregnation (Foot's method). Giant cells are conspicuous and are darkened by the silver. In the bottom right hand corner is the subcapsular sinus ( $\times 110)$.

Fig. 5.-Collapsed body of ninth thoracic vertebrae between adjacent intervertebral discs in Case 1. Haematoxylin and eosin $(\times 7)$.

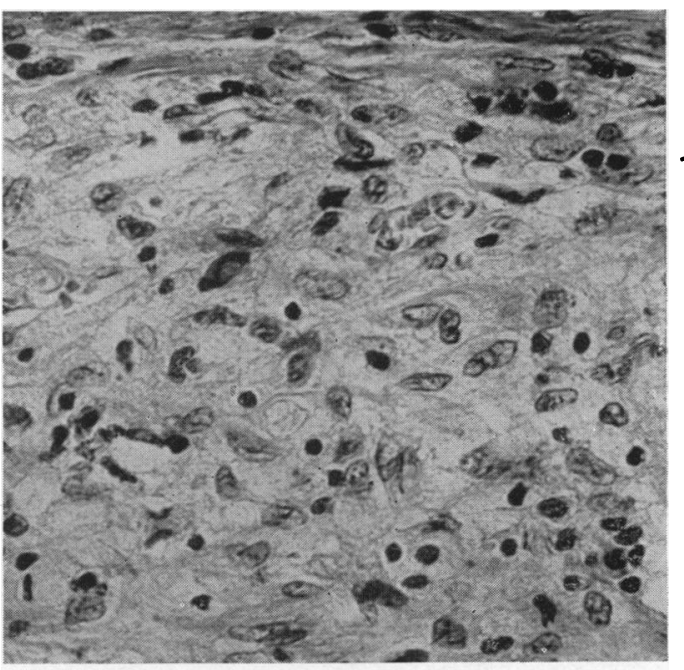

FIG. 2.

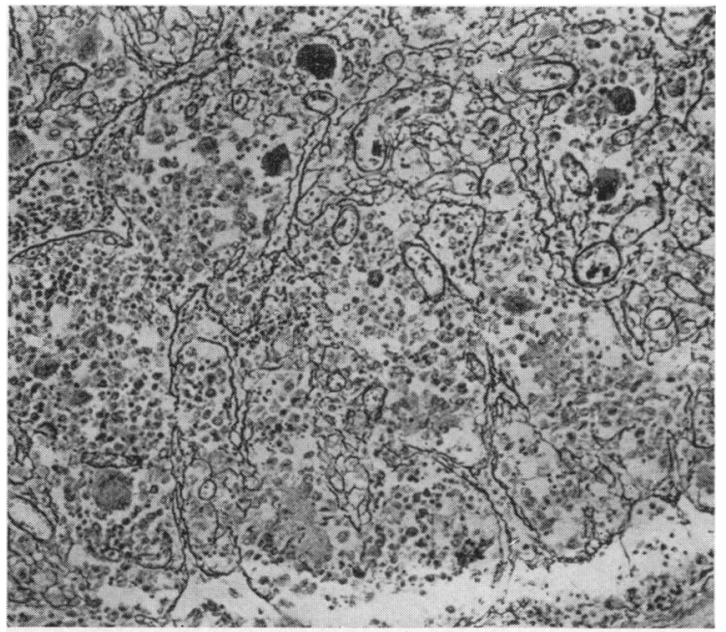

FIG. 4

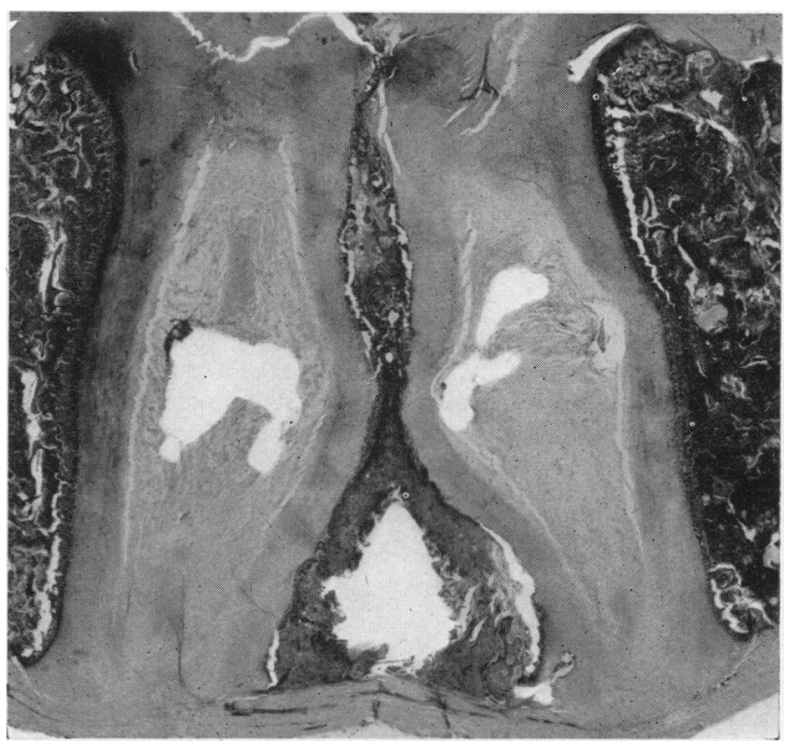

FIG. 5 
with proliferating mononuclear cells. The demarcations between the pulp and the remaining sinuses were lost and only a very cccasional ill-defined ring of small lymphocytes remained to indicate the site of the lymphoid follicles. Reticulin fibrils were not increased (Fig. 4). Giant cells were moderately numerous and foam cells, though present in scanty groups in the upper cervical gland, were not found elsewhere. The fat in the upper cervical gland had the same characters as that in the thymus. Eosinophil leucccytes were variable in numbers but were never abundant, and neutrophils were similarly distributed among the proliferating cells. Small haemorrhages were common and a scanty amount of iron pigment was associated with erythrophagocytosis by the mononuclear cells.

SPLEEN AND THYroID Gland. The spleen contained only one minute fccus of proliferating mononuclear cells in relation to the adventitia of a small arteriole. A small focus was also present in the thyroid gland between the acini. In the dural capsule surrounding the pituitary gland there were numerous foam cells and mononuclear cells with scanty eosinophil leucocytes, but the gland itself was not invaded.

THE Bones. Sections from the vault and base of the skull, from the left ninth rib, from the bodies of the eighth to the tenth thoracic vertebrae, from the head of the femur and of femoral marrow were examined. Except for the head of the femur, which appeared normal, all bone sections showed more or less extensive areas of mononuclear cell proliferation in the medullary spaces associated with bone destruction. This was especially marked in the body of the ninth thoracic vertebra (Fig. 5) where the space between the two intervertebral discs was occupied by a few partly necrotic bone fragments among a small number of proliferating cells. The marrow of the eighth and tenth thoracic bodies was extensively infiltrated and foam cells and giant cells were numerous. In the ninth left rib, which showed a pathological fracture, there was a little callus formation beneath the periosteum at one point over the fracture. Some fibrosis was present here but was not conspicuous in any of the other bone lesions. Eosinophils were not numerous in any bone lesion, though they were present in all, usually in association with an equal number of neutrophil leucocytes and a few small lymphocytes.

Sections from cerebral cortex, the floor of the third ventricle through the pituitary stalk, basal ganglia and hind-brain showed no histological abnormality. No abnormal changes were found in sections of either suprarenal glands, the posterior third of the tongue or of the oesophagus.

Case 2. Susan M., aged 1 year and 2 months, was admitted to The London Hospital on July 4, 1950. She was the only child of healthy parents and had been born six weeks before term after an otherwise normal pregnancy. Birth weight was $5 \mathrm{lb}$. $12 \mathrm{oz}$. The child was breast fed for two weeks only and the feeds were then changed to a dried cow's milk mixture.

At the age of 1 month the mother noticed a skin eruption which appeared in both groins. This was at first erythematous and later scaly in appearance. It appeared to irritate the child considerably at times, particularly at night and during periods of teething. At the age of 8 months a dermatologist had been consulted and a diagnosis of infantile eczema was made. Local applications produced only temporary improvement and the eruption gradually spread to involve the trunk, limbs and, more recently, the scalp. At no time had the face been affected.

At the age of 8 months (six months before admission) slight prominence and frequent watering of the right eye was noted. This had not worried the parents unduly, and it was not until a few weeks before she came into the hospital that the proptosis became more obvious. At this time a large mass was first noticed in the right side of the neck, and this rapidly increased in size. The child became fretful, looked pale, began to lose weight and excessive thirst was noted by the parents.

On admission the patient appeared extremely ill. She was very fretful, pale and moderately wasted. Her weight was $16 \mathrm{lb} .4 \mathrm{oz}$., the temperature $101^{\circ} \mathrm{F}$., pulse 152 and respirations 34 . The face was asymmetrical and there was also a moderate degree of plagiocephaly. Both eyes were prominent, the right showing obvious proptosis, and in the right temporal region there was a soft, smooth, fluctuant swelling extending backwards from the lateral angle of the orbit as far as the ear. Pressure on this swelling caused further protrusion of the right eye, and deep palpation revealed a defect in the underlying skull and lateral wall of the orbit.

The skin of the trunk and proximal parts of the limbs was covered by a diffuse scaly eruption, most

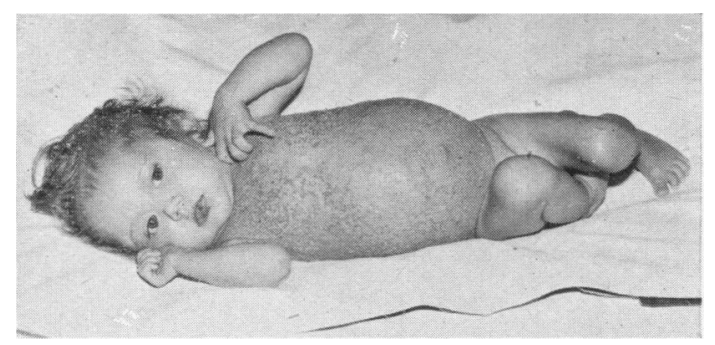

Fig. 6.-Photograph of Case 2 showing the scaling rash.

marked in the groins and axillae (Fig. 6). The scales were dry and brownish-red, although in some places they were separated by moist weeping areas. There were a few similar lesions on the scalp, but no part of the skin of the forehead and face was affected. There was no purpuric element in the eruption.

Both ears showed severe otitis externa, and a reddish polypoid mass was attached to the anterior wall of the right external meatus.

The lymph nodes in both groins and axillae were moderately large and discrete, and in the neck there was considerable enlargement of the tonsillar groups on the right side.

The abdomen was distended and a large smooth liver could be felt two inches below the costal margin. There 
was no palpable enlargement of the spleen, and no evidence of ascites.

The respiratory, central nervous and cardiovascular systems appeared quite normal.

The urine was turbid and a cloud of albumin was present; the deposit showed a considerable excess of pus cells. Culture produced a growth of Bact. coli, faecal streptococci and Proteus.

Blood examination showed: haemoglobin, $47 \%$ $(7.0 \mathrm{~g} . \%) ; 1$ e u c oc y te s, 17,000 per c.mm. (neutrophils $67 \%$, lymphocytes $32 \%$, monocytes $1 \%$ ). There was slight anisocytosis

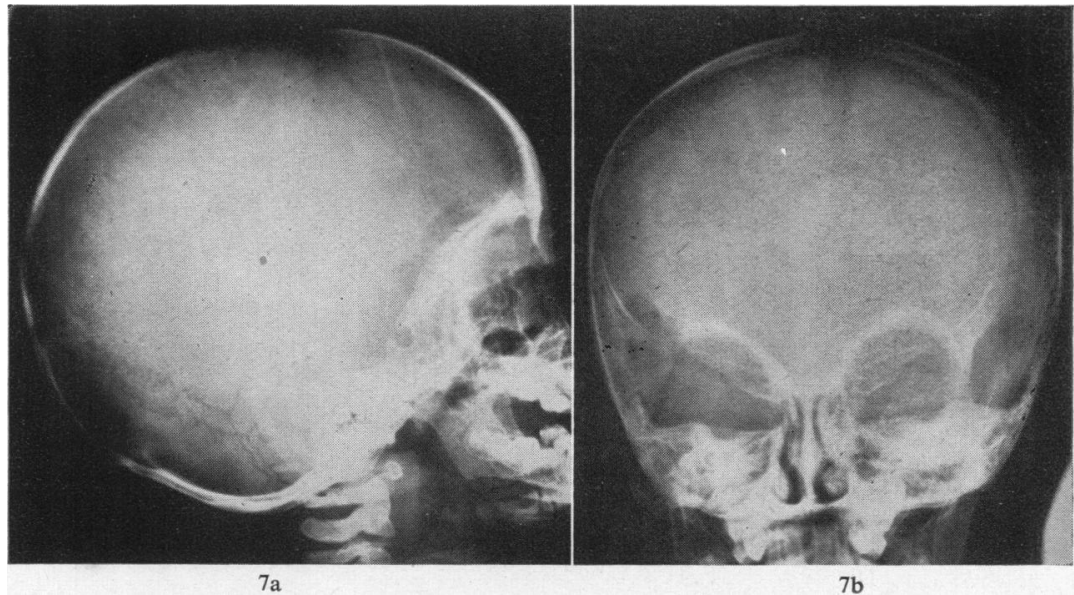

FIG. 7.-Frontal and lateral radiographs of skull of Case 2 showing the sharply defined bony defect in the right temporal region.

and polychromasia of red cells. The platelets were plentiful.

Radiographs of the skull (Figs. 7a and b) revealed a large area of bone destruction on the right side involving the squamous portion of the temporal bone, and also the posterior and lateral walls of the orbit. Radiographs of the long bones taken after death did not show any further bony defects.

A clinical diagnosis of Hand-Schüller-Christian disease was made, with neuroblastoma of the suprarenal as a likely alternative.

In view of the child's poor general condition and the extent of the lesions the prognosis was considered hopeless, and the treatment was restricted to symptomatic measures. Soon after admission the patient developed signs of bronchopneumonia and she died on the fifth day.

\section{Pathological Findings}

Necropsy (P.M. 253/50) was performed 17 hours after death. The results showed respiratory failure, and HandSchüller-Christian disease with infiltration of the thymus, spleen, liver, lymph nodes, lungs and skull bones.

Macroscopic Appearances. The following were noted.

Thymus. The gland was slightly shrunken and replaced by nodular opaque bright yellow and greywhite rubbery tissue with occasional softer grey areas.

LYMPH NODES. These were generally enlarged with soft purple and grey cut surfaces flecked with petechial haemorrhages. The upper cervical groups were largest (measuring up to $3.5 \times 2.5 \times 2 \mathrm{~cm}$.) and showed opaque yellow flecks on section. The paracolic, iliac and lumbar groups were less conspicuously enlarged.

SpleEN. The spleen $(21 \cdot 3$ g.) was rather firm, slightly enlarged, with on the cut surface, conspicuous Malpighian bodies and ill-defined grey areas (up to $0.4 \mathrm{~cm}$. diameter), in the pulp.

LIVER. The liver $(382.7$ g.) was fatty and buff coloured.

Lungs. The lungs were poorly aerated and, on section, the surfaces were studded with numerous grey and yellow nodules (up to $3.5 \mathrm{~cm}$. diameter) showing occasional small cysts at their peripheries.

SKULL. The skull was asymmetrical, the right half being skewed anteriorly, due to a mass of mahoganybrown and grey tissue mottled with yellow which both infiltrated the right temporalis muscle and fascia and occupied a bony defect $(3 \mathrm{~cm}$. diameter) in the right squamous temporal bone and the adjacent lateral orbital wall. The orbital contents were unaltered. Similar yellow and grey infiltration involved the lateral aspects of the pituitary fossa spreading into the cavernous sinuses, and there was a band of infiltrating tissue in the basisphenoid beneath the sella turcica. The middle ears contained grey exudate flecked with yellow. Tissue of the same nature also infiltrated the dura around the torcular herophili, but the skull here was intact.

SkIN. A diffuse, silvery-brown scaling rash, in parts hyperkeratotic, in parts with shallow ulceration, covered the entire front and back of the trunk, most marked over the abdomen and the chest, reaching from the occiput and shoulders to the axillae and down to the groins. The skin of the arms, legs and face was clear, except for a punctate rash on the palms and soles.

The right femur and humerus, the sternum, the heart $(49.6 \mathrm{~g}$.), the gastro-intestinal tract, the thyroid $(1 \cdot 25 \mathrm{~g}$.), the suprarenal glands $(6 \cdot 5 \mathrm{~g}$.), the kidneys $(77 \cdot 2 \mathrm{~g}$.), and the genito-urinary tract showed no abnormality.

The body weighed $6.55 \mathrm{~kg}$.

Microscopical Examination. Paraffin sections were prepared as in Case 1.

LYMPH NODES. The normal architecture of all nodes examined was almost entirely replaced by sheets and ill-defined nodules of actively proliferating irregular plump cells with eosinophil, faintly granular cytoplasm, and pale staining oval, often twisted, nuclei. Nucleoli were not visible in the majority, but a few larger cells with conspicuous nucleoli were seen. Many binucleate, and a moderate number of multinucleate giant cells were present. The capsules were everywhere intact, though a few mononuclear cells were occasionally found 


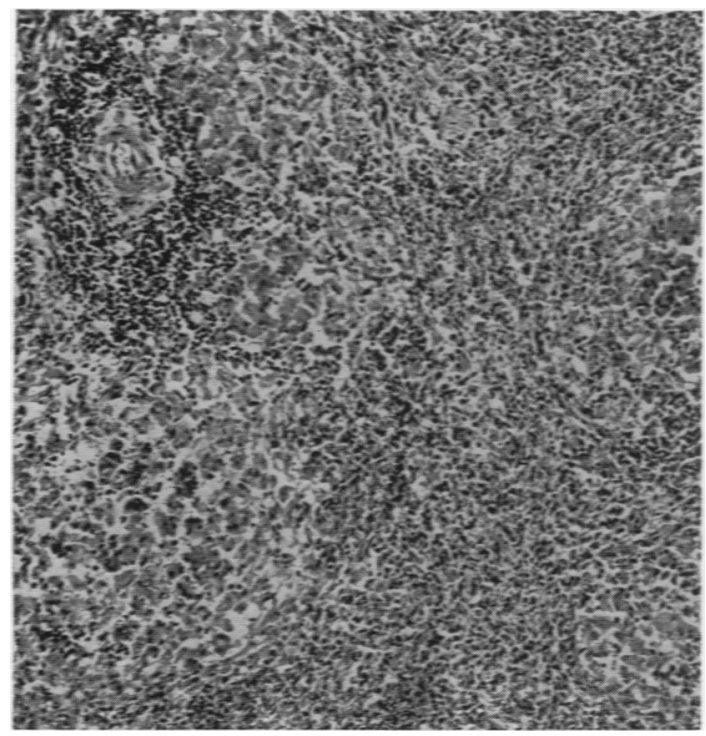

Fig. 8.-Spleen of Case 2: sharply circumscribed nodules of histiocytes in the pulp. Hacmatoxylin and eosin $(\times 110)$.

in the perinodal connective tissues. In one of the right upper cervical nodes narrow compressed strands of small lymphocytes formed broken rings in the expected position of the lymphoid follicles, suggesting that proliferation of mononuclear cells had occurred within the follicles as well as in the medullary pulp. The subcapsular sinuses were filled with cells, but elsewhere the pattern of sinuses and medullary cords was lost. There was no increase in reticulin fibrils, and no fibrosis. A few foam cells were found in the right upper cervical node but in none of the others. Eosinophils were scanty and in equal numbers with neutrophil leucocytes. Small haemorrhages had occurred regularly in many nodes, and the mononuclear cells around these were actively phagocytic of red cells while some contained a little iron pigment. Cccasional small foci of necrosis were seen in the nodular collections of cells.

SPLEEN. Discrete nodules of mononuclear cells were scattered closely throughout the section (Fig. 8): they were not related to the Malpighian bodies which were atrophic and consisted of small lymphocytes only. Microscopic haemorrhages were present in several of the nodules and erythrophagocytosis and a little iron pigment were seen in the adjacent cells. There were no foam cells. Eosinophils were scanty. There was a slight increase in reticulin fibrils around the nodules but none within them. With the Weil-Davenport method most of the mononuclear cells were strongly argyrophilic and showed plump cell bodies with irregular processes. A similar result was obtained with silver preparations from lymph nodes.

Thymus. The gland was completely replaced by a network of coarse bundles of collagen fibres and spindle fibroblasts, within the interstices of which were numerous closely packed mononuclear cells similar to those else- where. Foam cells were numerous, especially adjacent to the collagen bundles, but not in the centres of the cellular areas. No eosinophils were seen, though small lymphocytes were present in scanty groups.

LIVER. There was a similar infiltration in many portal tracts u naccompanied by foam cells, fibrosis or eosinophils.

LUNGS. Nodules of mononuclear cells with abundant associated reticulin fibrils and numerous foam cells destroyed the alveolar architecture over large areas. Collagen fibres were abundant focally in the nodules, but eosinophils were very scanty. Considerable dilatation of many alveolar spaces, infundibula and terminal bronchioles was found in the neighbourhood of these nodules.

Pitumary Gland. The capsule of the gland was heavily infiltrated with cells amongst which foam cells were numerous, but the gland itself was intact. A similar infiltration was present in the dura from the torcular herophili.

Skull Bones. The basisphenoid, the right lesser wing of the sphenoid, and the right middle fossa showed extensive destruction of bone with replacement by infiltrating tissue with numerous foam cells and multinucleate giant cells, but both eosinophils and fibrosis were inconspicuous, the last mainly covering the surfaces of the cellular masses.

SkIN. The superficial layers of the corium were occupied by irregular, non-foamy, mononuclear cells and focal ulceration of the overlying epidermis was seen (Fig. 9).

Sections of the thyroid gland, the suprarenal glands and the posterior mitral cusp did not reveal any abnormality. Careful examination of the brain sections taken from the floor of the third ventricle, both caudate nuclei, and occipital and parietal regions of the brain after some weeks' hardening in formalin showed no histological abnormality.

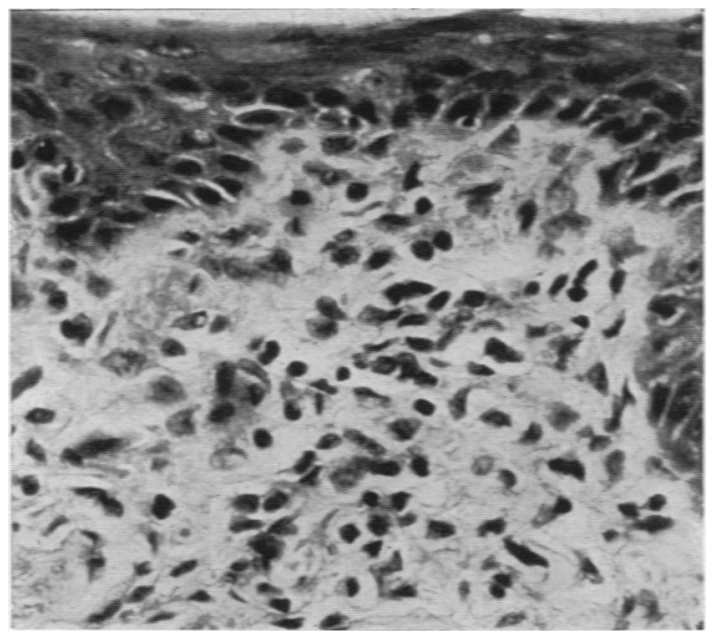

FiG. 9.-Skin of abdomen in Case 2 showing proliferating histiocytes in the subepidermal layer. Haematoxylin and eosin ( 425). 
Lipoid Studies on Case 2. Frozen sections from blocks of tissue fixed in formol-calcium were examined with Sudan III and Sudan black B. Plentiful sudanophilic lipoid droplets were seen in the foam-cell areas of the thymus, and sections from the same regions, stained with Nile blue sulphate, showed a moderate amount of purple-staining material indicating the presence of neutral fats; examination with the polarizing microscope revealed abundant anisotropic lipoid, which disappeared on gentle heating and reappeared on cooling as 'Maltese crosses '; the Schultz reaction was strongly positive and digitonide crystals formed in large numbers. It was concluded from these findings that a mixture of neutral fats, cholesterol and cholesterol esters was present. The Smith-Dietrich stain and Baker's (1946) acid haematin-pyridine procedure for phospholipins both showed a considerable amount of indigo-blue staining lipoid material in the foam-cell areas, but in view of Lison's (1936) warning concerning the interpretation of the Smith-Dietrich stain in the presence of cholesterol and its esters, no definite conclusion as to the presence of phospholipins in the lipoid mixture could be reached.

A similar mixture of fatty substances was found in the lesions in the lungs and in the mass from the right lesser wing of the sphenoid, but only scanty quantities of sudanophil and anisotropic fat were detected in one coeliac and one right upper cervical lymph node. No lipoid substances were found in the spleen, the portal infiltration in the liver or in the skin lesions. The above qualitative results appear to agree with quantitative lipoid studies, quoted by Thannhauser (1950b) on lesions in Hand-Schüller-Christian disease.

\section{Discussion}

Hand-Schüller-Christian disease is usually recognized as a chronic disorder chiefly affecting children and adolescents, of which the pathological basis is a multifocal proliferation of histiocytes associated with the presence of lipoid, predominantly cholesterol and its esters. In addition, eosinophils are usually conspicuous in the lesions. The classical triad of diabetes insipidus, exophthalmos and bone deposits is by no means a constant finding, for the clinical picture is extremely variable and depends largely on the situations involved in the disease process. The bones are especially affected, and involvement of the viscera is not uncommon.

The majority of cases occur under the age of 12 years, and the maximum incidence is in the second, third and fourth years of life (Dauksys, 1935). Onset of the disease in the first year of life is unusual.

A disease peculiar to infants and young children which is characterized pathologically by histiocyte proliferation, but no lipoid-containing foam cells in the affected tissues, has been called Letterer-Siwe disease by Abt and Denenholz (1936). Siwe $(1933,1949)$ describes the condition as a disease of unknown aetiology with an acute or subacute onset, fever, progressive anaemia, purpuric skin rashes, hepato-splenomegaly and localized bone defects. These last may not be detected clinically but, according to the author, are always present histologically. The outcome is invariably fatal after an illness which may last for several months. Siwe emphasizes that cells containing fat are not prominent in the lesions and lipoid-containing foam cells are not to be found. There are about 30 reports of the disease in the world literature but examples in the British literature are very few, the first being the cases recorded by Gittins (1933) and the most recent that of Claireaux and Lewis (1950). The latter paper reviews the condition and summarizes current views concerning the relationship between Letterer-Siwe disease, Hand-SchüllerChristian disease and eosinophilic granuloma of bone. The last term is applied to a solitary destructive lesion in bone, occurring chiefly in children and young adults, which is regarded by most authors as a unifocal manifestation of HandSchüller-Christian disease. Spontaneous healing by resolution (Jaffe and Lichtenstein, 1944) or by fibrosis with or without lipidization (Green and Farber, 1942) is the common result.

The evidence in favour of the essential unity of these conditions has been steadily accumulating. Glanzmann (1940) remarked upon the resemblance between the bone lesions in Hand-SchüllerChristian disease and Letterer-Siwe disease, and the similarity of the basic pathology has been reviewed by Wallgrén (1940), Jaffe and Lichtenstein (1944) and others. Following these publications attention has been drawn to cases with transitional features which appear to link up the two conditions; for example, Wallgren's (1940) two cases and the report of Flori and Parenti (1937).

Our primary concern in reporting these two cases is to indicate their relationship to the acute form of reticulosis in infants (Letterer-Siwe disease) and also to the more chronic disease found as a rule in older children (Hand-Schüller-Christian disease).

In both children the disease began in early infancy. In Case 1 the lesions in the roof of the mouth were probably not significant and, after initial feeding difficulties, the child progressed normally until the age of 4 months, when enlargement of the cervical lymph nodes was first observed. She died, five months later, after a steadily progressive course. Case 2 is particularly interesting in that skin lesions appeared at the age of 1 month, and this was undoubtedly the first manifestation of the disease. A period of just over one year elapsed from the onset of symptoms until death. In respect of duration of the illness and their age, 
therefore, these two children resemble many other reported cases of Letterer-Siwe disease. Further resemblances to this condition were found in the appearance of fever, anaemia, enlarged lymph nodes, hepato-splenomegaly and bone defects (multiple in the first and confined to the skull in the second case). They differ from the accepted clinical concept of Letterer-Siwe disease, however, and resemble Hand-Schüller-Christian disease by the presence of radiological evidence of pulmonary involvement in the first case, and of exophthalmos and an extensive skin eruption in the second case. In fact, Case 1 was included in a series of cases in a paper on 'honeycomb lungs' by Oswald and Parkinson (1949, Case 1) in which they discussed similar changes in other reported cases of HandSchüller-Christian disease.

Siwe (1949) has stressed the frequent occurrence of petechial skin lesions as part of the disease described by him, although some of the cases accepted as examples of Letterer-Siwe disease have not shown this feature. Furthermore, petechia-like lesions are not rare in cases of Hand-SchüllerChristian disease (Thannhauser, 1950a). Reye (1948) records the appearance of a petechial skin rash in a case of Letterer-Siwe disease eight months before death and, although he does not mention the clinical progress of the skin lesions, the postmortem description of the rash and the histological appearances closely resemble those of our second case. So far as is known there was no clinical evidence of skin involvement in our first case and none was found at necropsy; there was certainly no petechial element in the scaly eruption of Case 2 . This is of considerable interest, for the child presented with a flexural eruption and, although the lesions progressed to affect the trunk and scalp, there was never any involvement of the face such as is usually seen in cases of infantile eczema. A similar affection of the skin with the same distribution and reddish-brown scaly appearance is known to occur in cases of Hand-Schüller-Christian disease (Merritt and Paige, 1933; Lane and Smith, 1939; Curtis and Cawley, 1947), but has not, so far as we know, been reported in cases of Letterer-Siwe disease other than in the one described by Reye.

At necropsy there was a remarkable similarity between our two cases. Both showed widespread visceral changes and focally destructive bone lesions. Conspicuous in both were deposits of yellow lipoid material most noticeable in the thymus, the lungs and the bone lesions. Although macroscopically the disease appeared without doubt to be in each case Hand-Schüller-Christian disease, on microscopical examination several features deviated from the descriptions of that disease by Fraser (1935) and Englebreth-Holm, Teilum and Christensen (1944) in such ways as at first to cast some doubt on the diagnosis. According to these authors the mature lesions of Hand-SchüllerChristian disease consist of a proliferation of histiocytes with numerous fat-laden foam cells, eosinophil leucocytes and a variable number of collagen fibres. It has been seen that eosinophils were not a conspicuous feature in any part of these two cases, and fibrosis and foam cells were only focal features in the thymus and lung lesions, while in the lymph nodes the changes consisted largely of proliferating histiocytes, and foam cells were very rarely found. It was in this last site in both cases, and in the spleen in Case 2, that the changes were most reminiscent of Letterer-Siwe disease. In this condition there is a widespread histiocytic proliferation in viscera and bones unaccompanied by fat accumulation, while most authors make little mention of the presence of eosinophil leucocytes, and fibrosis is not seen. The absence of lipoid in the lesions is one of the cardinal points in the arguments of Abt and Denenholz and of Siwe himself for separating this condition sharply from Hand-Schüller-Christian disease. Their arguments are, however, considerably weakened by the report of a case by Flori and Parenti (1937) of an infant in whom a lymph node biopsy performed 10 months before death showed a non-lipoid reticulo-endothelial hyperplasia, while at necropsy widespread lipoid deposits and fibrosis were found in many organs, including the thymus gland. Again eosinophils were inconspicuous in their case, and in this as well as in most other features the changes were closely similar to those in our two cases. Flori and Parenti regarded their case, on clinical as well as pathological grounds, as one of Hand-Schüller-Christian disease and it has been accepted as transitional between this condition and Letterer-Siwe disease by most authors. Siwe on the other hand regarded this case as atypical Hand-Schüller-Christian disease and not related to the condition bearing his name because of the lipoid accumulations. Wallgren, however, pointed out that lipoid deposits and fibrosis could be related to the chronicity of the condition and were not primary features in the disease process. Further, Fraser (1935), and Englebreth-Holm, Teilum and Christensen (1944), showed that the earliest phase of Hand-Schüller-Christian disease was a pure proliferation of histiocytes while the other features of the histology emerged in various stages subsequently. Attention has been paid in this study to the presence or absence of eosinophil 
leucocytes in both cases, the relative paucity of which contrasts with the descriptions of HandSchüller-Christian disease by the authors mentioned. The rôle of eosinophil leucocytes in tissue reactions is uncertain and it is difficult at this stage to attach much significance to their scarcity here, but attention is drawn to a case reported by Jaffe and Lichtenstein (1944) of a 10-month-old girl with a typical eosinophilic granuloma of bone on which a biopsy was performed. The infant died after a short illness and at necropsy the lesions were described by the authors as those of Letterer-Siwe disease; they also noted the curious absence of eosinophil leucocytes, so prominent in the biopsy specimen. Whatever their rôle, it is undoubtedly a secondary one in the disease process, and variations in their number must not be allowed to obscure the essential abnormality of histiocytic hyperplasia fundamental in the pathology of Hand-Schüller-Christian disease, and which appears to be shared by Letterer-Siwe disease.

As to the nature of the predominant cell concerned in these two cases which has thus far been variously termed a mononuclear cell, a histiocyte or a reticulo-endothelial cell, attention has been drawn to its ability to ingest red cells and to store fatty substances and haemosiderin, properties characteristic of macrophages, the phagocytic cells of Aschoff's (1924) reticulo-endothelial system. According to Maximow (1924) the macrophage system of cells consists, in essence, of the phagocytic reticular cells, the free macrophages, and the sinuslining cells of the lymph nodes and of the spleen. On morphological grounds, using aniline dyes alone, it is not possible in the absence of intracytoplasmic ingested particles to separate the first of these three chief groups of cells of the system from the 'reticulum' cells, the primitive stem cell defined by Robb-Smith (1938). By the application, however, of silver impregnation techniques developed by Hortega del Rio and de Asúa (1921), and subsequently used extensively by Robb-Smith and by Marshall $(1946,1950)$, it has been shown by these last two authors that whereas the 'reticulum' cell is not impregnated, the cells of the macrophage system are intensely blackened. By applying this criterion of argyrophilia in these two cases it was possible to identify the cells concerned as cells of the macrophage system (histiocytes) even where they were showing no phagocytic activity. Furthermore it was apparent that they tended to deviate to a moderate degree from the normal morphology, being rather larger, more irregular and more plump than is generally found, but no great pleomorphism was seen nor was there any evidence to suggest that the proliferation was anything other than a hyperplasia. Moreover, despite the fact that the architecture of the lymph nodes was greatly obscured, the impression was gained that the proliferation was primarily medullary in origin. It might be reasonable, therefore, to enquire whether this acute variety of Hand-Schüller-Christian disease is in any way related to the disease described by Scott and Robb-Smith (1939) and named 'histiocytic medullary reticulosis '. In brief, this is a disorder affecting adults from the third to the seventh decades, and its main features are high fever, moderate lymph node and splenic enlargement, signs of acute haemolytic anaemia, and occasional petechial skin eruptions. The course is rapid and death occurs in a few months after the onset of the symptoms. In the few recorded cases neither bone lesions, exophthalmos nor diabetes insipidus have been observed. From the descriptions given by these authors and from the study of two unpublished cases from the records of this Institute which amply fulfilled the diagnostic criteria of the disease, it is apparent that, histologically, there is an unusually active proliferation of histiocytes in the lymph nodes and spleen, many bizarre forms being present, and especially noteworthy are occasional multinucleate cells resembling Sternberg-Reed giant cells, as the photomicrographs of Scott and RobbSmith show. Haemorrhages are abundant in the lesions and erythrophagocytosis is a prominent feature, explaining, perhaps, the clinical finding of haemolytic anaemia, as suggested by McGovern, Morrow and Thomson (1951). Although the presence of fat in the lesions is not mentioned by the original authors, a study of our material shows that while many of the histiocytes contained cytoplasmic vacuoles of variable size in paraffin sections, no mature foam cells could be found and the frozen sections made in one case did not reveal any but the scantiest quantity of sudanophil lipoid. No fibrosis was present, as might be expected if this feature is to be regarded as a phenomenon of chronicity, and eosinophil leucocytes were but scanty in the lesions.

It appears, therefore, that histiocytic medullary reticulosis includes a number of features in common with the acute form of Hand-Schüller-Christian disease. Clinically they both run a rapid course, with lymph node and spleen enlargement, fever, and sometimes petechial rashes, while the pathological basis in both is histiocytic proliferation. The differences, however, are more striking. In the first place the age incidences have nothing in common, though in an attempt to relate the conditions more closely this point might conceivably 
be used to help explain away other differences such as the absence of readily observable bone changes. Secondly, the atypical nature of the cells and the pronounced tendency towards red cell destruction must both be regarded as fundamentally peculiar to histiocytic medullary reticulosis, stamping its character both pathologically and clinically. While it is possible that there may be some connection aetiologically between the two conditions, the small number of published cases of histiocytic medullary reticulosis and the absence of any cases which could conceivably be considered as transitional between it and Hand-Schüller-Christian disease, together with the differences listed above, bring us to the conclusion that there is at present no justification for relating them except in so far as they are diseases of the same cell system.

On the other hand the mere existence of a histiocytic hyperplasia, as in histiocytic medullary reticulosis, which does not appear to be concerned with lipoid storage and is apparently unrelated to Hand-Schüller-Christian disease, does lend some support to Siwe's conception of the disease bearing his name. Those authors who have accepted the unity of Letterer-Siwe disease and Hand-SchüllerChristian disease, have done so believing that the cases reported in which no lipoid storage was found would have developed this feature if their course had been more protracted. Siwe contends that this need not necessarily be true since some non-lipoid cases have lived considerably longer than others which showed abundant lipoid storage in the lesions. It is obviously very difficult to decide either way in any particular case in the absence of biochemical and histochemical evidence of the metabolic capabilities of the cells concerned, but it is conceivable that some cases of acute histiocytic hyperplasia in infants do not store lipoid because the cells concerned are not functionally capable of doing so. It is suggested therefore that the term 'Letterer-Siwe disease' be maintained where at necropsy no lipoid changes are to be found in any case of acute histiocytic hyperplasia in infants, while the presence of lipoid with the appropriate characters should require that the term
' acute form of Hand-Schüller-Christian disease' be used.

Summary
Clinical and pathological details of two cases of Hand-Schüller-Christian disease in infants are described in full and the resemblances to the changes in Letterer-Siwe disease are discussed.

The relationship between these two conditions and histiocytic medullary reticulosis is discussed.

It is concluded that there is some pathological evidence for considering Letterer-Siwe disease as distinct from the acute form of Hand-SchüllerChristian disease.

It is a pleasure to thank Professor D. S. Russell and Dr. K. H. Tallerman, M.C., for their helpful advice and criticisms.

Our thanks are also due to Dr. K. H. Tallerman and Dr. Frank Ellis for permission to make use of the hospital notes of these two patients, and to Mr. John King, of the Photographic Department, for the photographs.

\section{REFERENCES}

Abt, A. F. and Denenholz, E. J. (1936). Amer.J. Dis. Child., 51, 499. Aschoff, L. (1924). Lectures on Pathology. New York.

Baker, J. R. (1946). Quart. J. micr. Sci., 87, 441.

Claireaux, A. E. and Lewis, I. C. (1950). Archives of Disease in Childhood, 25, 142.

Curtis, A. C. and Cawley, E. P. (1947). Arch. Derm. Syph., Chicago, 55, 810 .

Dauksys, J. (1935). J. Mo. med. Ass., 32, 466.

Englebreth-Holm, J., Teilum, G. and Christensen, E. (1944). Acta med. scand., 118, 292.

Flori, A. G. and Parenti, G. C. (1937). Riv. Clin. pediat., 35, 193.

Fraser, J. (1935). Brit. J. Surg., 22, 800.

Gittins, R. (1933). Archives of Disease in Childhood, 8, 367.

Glanzmann, E. (1940). Ann. paediat., Basel, 155, 1.

Green, W. T. and Farber, S. (1942). J. Bone Jt Surg., 24, 499. Hematol. Madr., 2, 161. Quoted by Marshall and White, 1950 .

Jaffe, H. L. and Lichtenstein, L. (1944). Arch. Path., Chicago, 37 99.

Lane, C. W. and Smith, M. G. (1939). Arch. Derm. Syph., Chicago, 39, 617.

Lison, L. (1936). Histochimie Animaie, p. 205. Paris.

McGovern, V. J., Morrow, A. W. and Thomson, E. F. (1951). J. Path. Bact., 63, 340.

Marshall, A. H. E. (1946). Ibid., 58, 729.

(1948). Ibid., 60, 515 .

and White, R. G. (1950). Brit. J. exp. Path., 31, 157.

Maximow, A. A. (1924). Physiol. Rev., 4, 533. Merritt, K. K. and Paige, B. H. (1933). Amer. J. Dis. Child., 46,

Oswald, N. and Parkinson, T. (1949). Quart. J. med., n.s. 18, 1.

Reye, R. D. K. (1948). Med. J. Aust., 2, 509.

Robb-Smith, A. H. T. (1938). J. Path. Bact., 47, 457.

Scott, R. B. and Robb-Smith, A. H. T. (1939). Lancet, 2, 194.

Siwe, S. A. (1933). Z. Kinderheilk., 55, 212.

(1949). Advanc. Pediat., 4, 117.

Thannhauser, S. J. (1950). Lipidoses. New York. (a) p. 366, (b) p. 417.

Wallgren, A. (1940). Amer. J. Dis. Child., 60, 471. 